\title{
Postangioplasty Restenosis Rate Between Segments of the Major Coronary Arteries
}

\author{
Walter R. M. Hermans, MD, Benno J. Rensing, MD, Johannes C. Kelder, MD, \\ Pim J. de Feyter, MD, and Patrick W. Serruys, MD
}

\begin{abstract}
Conflicting data have been published regarding the rate of postangioplasty restenosis observed in diverse segments of the coronary tree. However, these studies may be criticized for their biased selection of patients, methods of analysis, and definitions of restenosis. In the present study, 1,353 patients underwent a successful coronary dilatation of $\geq 1$ site. In all, 1,234 patients $(91 \%)$ had a follow-up angiogram after 6 months, or earlier when indicated by symptoms. All films were processed and analyzed at the thoraxcenter core laboratory with the coronary angiography analysis system (automated contour delection). Restenosis was considered present if the diameter stenosis at follow-up was $>50 \%$. No differences in restenosis rates were observed between coronary segments using this categorical definition. A continuous approach was also used; absolute changes in minimal luminal diameter adjusted for vessel size were used in order to allow comparison between vessels of different sizes (relative loss). No significant differences were observed between the coronary segments with this continuous approach. These results suggest that restenosis is a ubiquitous phenomenon without any predilection for a particular site in the coronary tree.
\end{abstract}

(Am J Cardiol 1992;69:194-200)

From the Catheterization Laboratory, Thoraxcenter, Erasmus University, Rotterdam, the Netherlands. Manuscript received June 17, 1991; revised manuscript received and accepted August 6, 1991.

Address for reprints: Patrick W. Serruys, MD, Catheterization Laboratory, Thoraxcenter, Erasmus University, P.O. Box 1738, 3000 DR Rotterdam, the Netherlands.
$\mathrm{E}$ ver since the introduction of percutaneous transluminal coronary angioplasty (PTCA) ${ }^{1}$ as an alternative to coronary artery bypass grafting, this means of treatment has been plagued by the problem of restenosis, which has become an important field of investigation in interventional cardiology. During the last 14 years clinicians have searched extensively for factors increasing the risk of restenosis, and many patient-lesion-procedure-related factors have been put forward. ${ }^{2,3}$ However, the cause and effect relation of these factors can be questioned, because these early studies were, in general, retrospective analyses with relatively small numbers of patients. In addition, these studies were fraught with methodologic problems; angiographic follow-up was incomplete, incidence of restenosis was influenced by the recurrence of symptoms, and time for restudy was not predetermined. Furthermore, the definition of restenosis varied between the different studies, and presence or absence of restenosis was assessed visually, a method known to be limited by inter- and intraobserver variability. ${ }^{4,5}$ One risk factor for restenosis that led to controversy is the site of dilatation, with some studies finding a higher incidence of restenosis in the proximal left anterior descending coronary artery (LAD) as compared with the right or left circumflex coronary artery (LC) (Table I). ${ }^{6-19}$ Recently, 2 multicenter restenosis prevention trials enrolled $>1,400 \mathrm{pa}-$ tients who were analyzed at the same angiographic core laboratory. In $91 \%$ of these patients, follow-up angiography was performed, and the same quantitative coronary angiographic method of analysis was used. ${ }^{5,20}$ The present study investigates whether the previously reported differences in restenosis rates in the 3 major coronary arteries could be confirmed in this large study group.

\section{METHODS}

The study population consisted of 1,442 patients with significant primary stenoses in native coronary arteries who were prospectively enrolled in 2 restenosis trials in Europe. Because no angiographic or clinical benefit of the 2 tested compounds could be demonstrated, the control and active treatment groups were pooled for the present study. PTCAs and follow-up films of all patients with successful dilations were analyzed at the thoraxcenter core laboratory. Informed consent was obtained in all cases before the PTCA procedure, and all patients were asked to return to the hospital for follow-up angiography. Patients with stable and unstable angina pectoris, and those with totally occluded vessel segments were included in the study. $\mathrm{Pa}$ - 


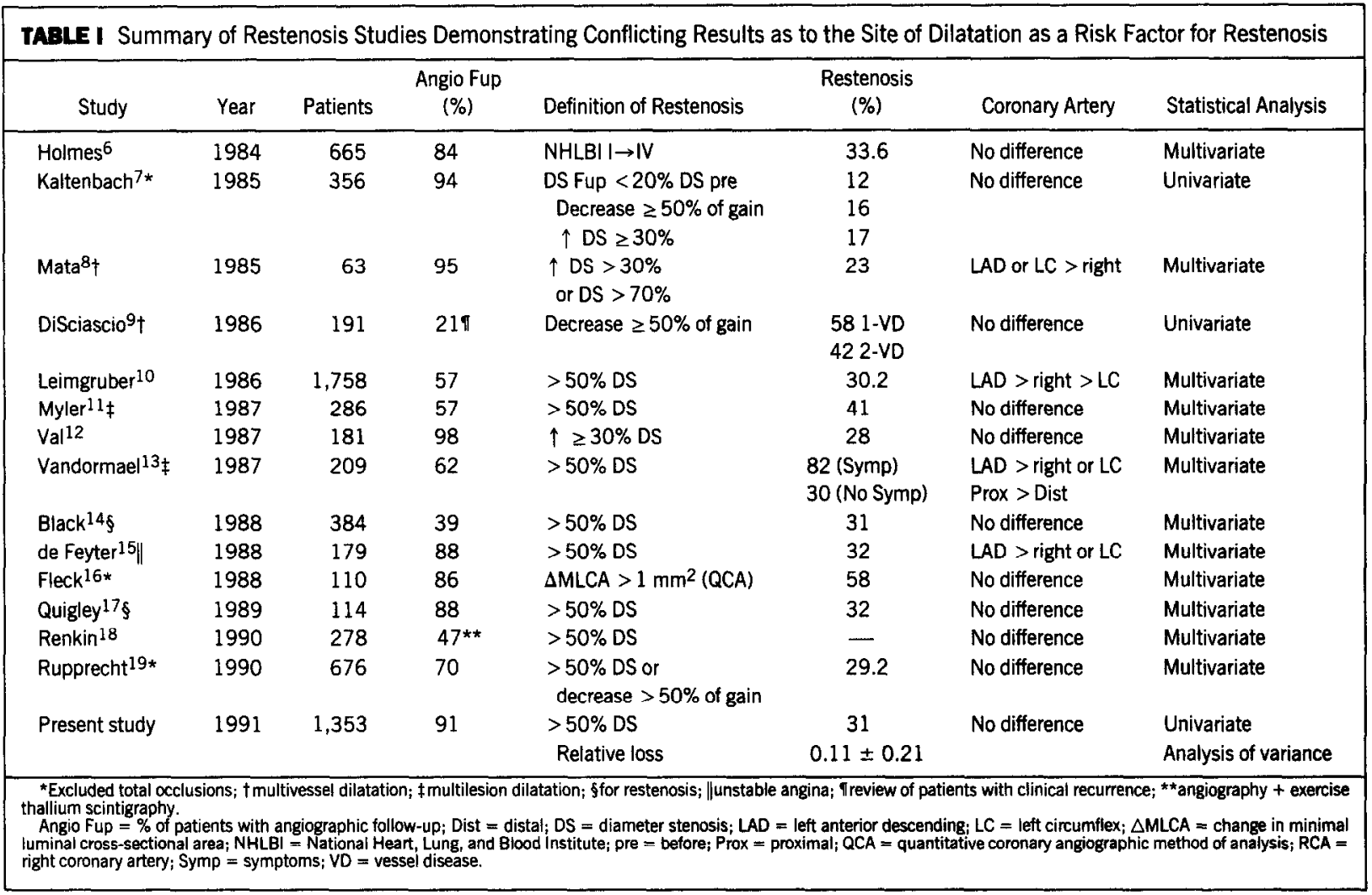

tients with developing myocardial infarctions and significant left main disease were excluded from the study. PTCA was successful if the final diameter stenosis was $<50 \%$ on visual inspection of the angiogram after PTCA. PTCA was considered complete when the guiding catheter was removed from the groin. When recurrence of chest pain during the hospital stay led to coronary reintervention, the film before reintervention was used as the follow-up angiogram. If a follow-up angiogram was obtained before 3 months and if no definite restenosis had occurred, the patient was asked to undergo another coronary angiogram at 6 months.

Figure 1 describes the flow chart of all 1,442 randomized patients. Of the 1,353 patients with successful PTCA, 1,234 patients had a follow-up angiogram after 6 months, or earlier when indicated for symptoms.

Percutanoous transhuminal coronary angioplasty procedure and angiographic andysis: At the beginning of the procedure, all patients received a bolus of intravenous heparin (10,000 IU). After 2 hours, an additional infusion of heparin (5,000 IU/hour) was administered until the end of the procedure. Use of a calcium antagonist for $\mathbf{4 8}$ hours was permitted. Choice of balloon type, inflation duration and pressure was left to the discretion of the operator.

Three angiograms were obtained of each patient (1 immediately before and 1 immediately after PTCA, and 1 at follow-up). The angiograms were recorded in such a way that they were suitable for quantitative analysis by the coronary angiography analysis system. An example of an analysis is shown in Figure 2. To standardize the method of data acquisition and to ensure exact reproducibility of angiograms after PTCA and at follow-up, measures were taken as described previously. 5,20

All cineangiograms were quantitatively analyzed using the coronary angiography analysis system that has been validated and described in detail previously. 5,20 The absolute values of the stenosis diameter as well as the reference diameter are measured by computer using the known contrast-empty catheter diameter as a scal-

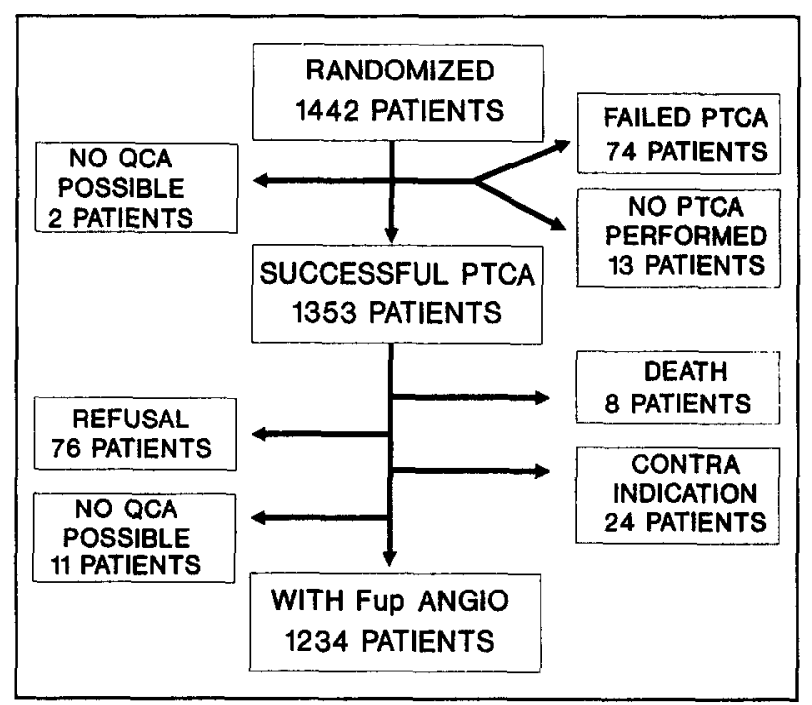

FICURE 1. Flow chart of 1,442 randemined patiente. In 74 patbents, andeplady procedure was unavececofut in 13, percutenoous trenduninal coronary andeplasty (PTCA) was not perfermed, and in 2, quantitative andysis (GCA) wes not poen chlo. Arejographic tollow-up (Fup ANeilo) was cbteined in 1,234 patients $(91 \%)$ affer evecessful coronary angloplasty in 1,353. 
ing device. For that purpose, the catheter tips were retained for accurate measurement with a micrometer. To achieve maximal vasodilation, either nitroglycerin $(0.1$ to $0.3 \mathrm{mg}$ ) or isosorbide dinitrate (1 to $3 \mathrm{mg}$ ) was administered for each coronary artery involved before and after PTCA, and at follow-up angiography. All contour positions of the catheter and the arterial segment were corrected for pincushion distortion introduced by the image intensifiers. Because the algorithm is not able to measure total occlusions and lesions with Thrombolysis in Myocardial Infarction-1 perfusion, a value of $0 \mathrm{~mm}$ was substituted for the minimal luminal diameter and $100 \%$ for the percent diameter stenosis. In these cases, the reference diameter after PTCA was substituted for the reference diameter before PTCA or at follow-up. For each dilated segment, the minimal luminal diameter and diameter stenosis before and after PTCA, and
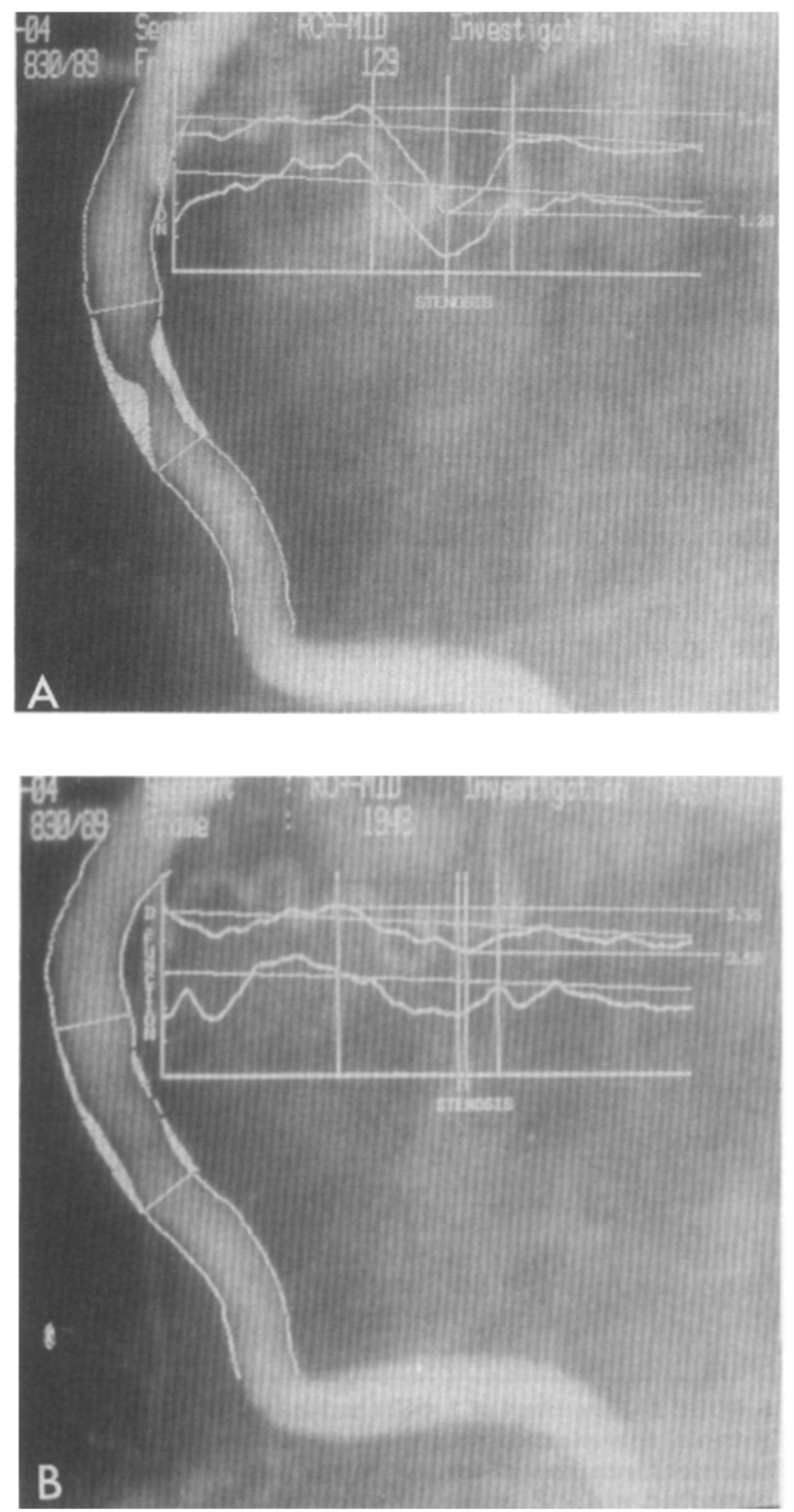

at follow-up were taken as the mean value from multiple matched projections. ${ }^{5}$

Definition of coronary segments: Austen et $\mathrm{al}^{21} \mathrm{di}-$ vided the coronary tree in 15 different segments (Figure 3). Because dilatation of the distal vessel segments did not occur frequently, it was decided to regroup these distal segments. The right coronary artery was divided in 4 segments; segment 1 corresponded with the proximal, segment 2 with the middle, and segments 3 and 4 were taken together as the distal right coronary artery. The LAD was divided in 5 segments; segment 6 corresponded with the proximal LAD, segment 7 with the middle LAD, and segments 8,9 and 10 were taken together as the distal LAD. The LC was divided in 5 segments; segment 11 corresponded with the proximal LC, segments 13 and 15 were taken together as the middle LC, and segments 12 and 14 were taken together as the distal LC.

Definition of restenosis: CATEGORICAL APPROACH: Many criteria have been proposed by the National Heart, Lung, and Blood Institute to assess restenosis. The most frequently used criterion by clinicians is that restenosis is present when the diameter stenosis is $>50 \%$ at follow-up angiography. ${ }^{22}$ This definition was used for our data.

CONTINUOUS APPROACH: In addition to this arbitrary categorical approach for restenosis, we wanted to use absolute changes in minimal luminal diameter adjusted for vessel size, which allows for comparison between vessels of different sizes and is a reflection of how the lesion behaves during and after PTCA.

Relative gain depicts the increase in minimal luminal diameter normalized for the reference diameter during PTCA (minimal luminal diameter [before PTCA after PTCA]/reference diameter before PTCA). Relative loss depicts the decrease in minimal luminal diameter normalized for the reference diameter (minimal lu-

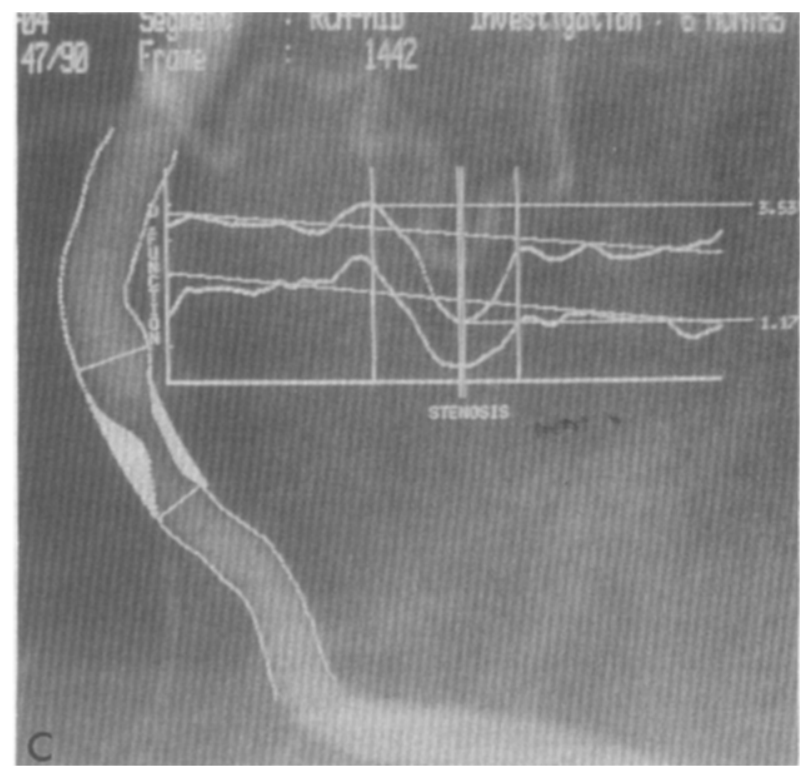

FCUFE 2. Shede frame andlograms of same besion of the itght coronary artery before dilatation (A), after dilatation (B) and at follow-tp (C). Arterlal boundarles detected by system are shown on anglogram; upper curve represents diameter function curve. Whinal hombial diamelor changes trom 1.28 before to $2.58 \mathrm{~mm}$ after perculaneous transluminal ceronary andoplacty. At follow-up 6 months later there is a docrease of minimal hminal diameter to $1.17 \mathrm{~mm}$. 
minal diameter [after PTCA - at follow-up]/reference diameter before PTCA) (Figure 4).

Data analysis: Data were analyzed using the biomedical-designed program statistical software package (University of California Press, Berkeley, California, 1990). A chi-square test was used to assess differences in categorical variables. A 1-way analysis of variance was used to assess differences in continuous variables among the 3 major coronary arteries and the 9 different segments of the coronary tree. A p value $<0.05$ was considered indicative of a significant difference.

\section{RESULTS}

The mean time to follow-up angiography was $165 \pm$ 42 days. In 1,234 patients, 1,452 lesions were successfully dilated (1.2 lesions/patient). In 74 patients, a totally occluded vessel segment was dilated. In $1,137 \mathrm{pa}-$ tients, 1-vessel dilatation was performed, 93 had 2-vessel dilatation, and 4 had all 3 vessels dilated. The majority of stenoses were located in the LAD (684 lesions) compared with 414 lesions in the right coronary artery and 354 in the LC.

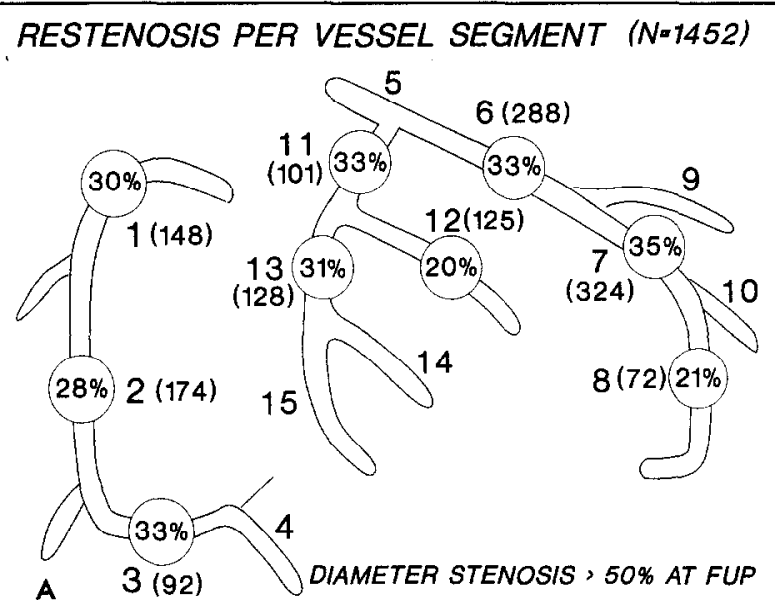

RELATIVE LOSS PER VESSEL SEGMENT

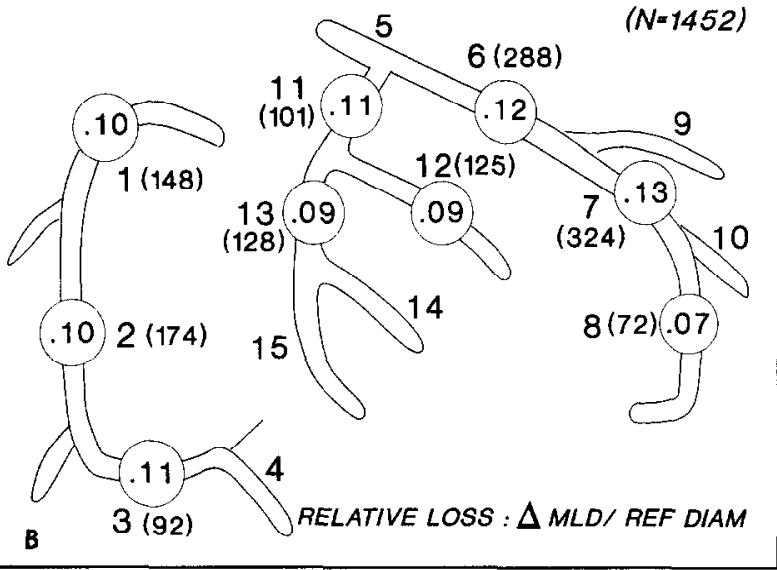

FGQURE 3. Coronary tree divided in 15 different segments with restenoels rate (using $>50 \%$ diamoter stenosts as criterion) for each segment (A), and relative lows per coronary segment (B) shown in circles. Between brackets are numbers of lealons dinted for that segment. FUP = follow-up. $\triangle M L D / R E F$ DIAM = docrease in minimal tuminal diameter normalized for reference dianeter.
Table II lists the results of the quantitative measurements of the 1,452 lesions. The largest vessel was the right coronary artery, with an average reference diameter of $2.86 \pm 0.55 \mathrm{~mm}$. The LAD and LC had similar sizes; the average reference diameters were $2.54 \pm 0.53$ $\mathrm{mm}$ for the LAD, and $2.55 \pm 0.50 \mathrm{~mm}$ for the LC (p $<0.001$ ). In addition, the average increases in minimal luminal diameter were $0.82 \pm 0.37 \mathrm{~mm}$ in the right coronary artery, $0.71 \pm 0.36 \mathrm{~mm}$ in the LAD, and $0.72 \pm$ $0.35 \mathrm{~mm}$ in the LC. If these values were "normalized for the reference diameter" (relative gain), no significant differences were observed among either the 3 major coronary arteries (right coronary artery vs LAD vs LC; $p=0.44$ ) or the different segments of the coronary tree $(p=0.77)$. During follow-up, the average losses in minimal luminal diameter were $0.26 \pm 0.55 \mathrm{~mm}$ in the right coronary artery, $0.30 \pm 0.48 \mathrm{~mm}$ in the $\mathrm{LAD}$, and $0.25 \pm 0.48 \mathrm{~mm}$ in the LC. If these values were normalized for the reference diameter (relative loss), no significant differences were observed among the 3 major coronary arteries (right coronary artery vs LAD vs LC; $p=0.13$ ) or the different segments of the coronary tree $(p=0.19)$.

The restenosis rate, and relative gain and loss for the 3 major coronary arteries and the diverse vessel segments, using either the categorical or continuous approach, are listed in Table III. No significant difference in either approach was observed.

\section{DISCUSSION}

Several investigators have raised the question as to whether the dilated vessel constitutes a risk factor for the development of restenosis. They have reported conflicting results (Table I). The question is becoming even more relevant as new interventional techniques (such as stenting, atherectomy, laser photoablation and rotablation) have been "claimed" to be more effective than conventional balloon angioplasty in certain lesion types (long lesions and total occlusions), locations or vessels (right coronary artery, LAD, LC and bypass graft), ${ }^{23}$

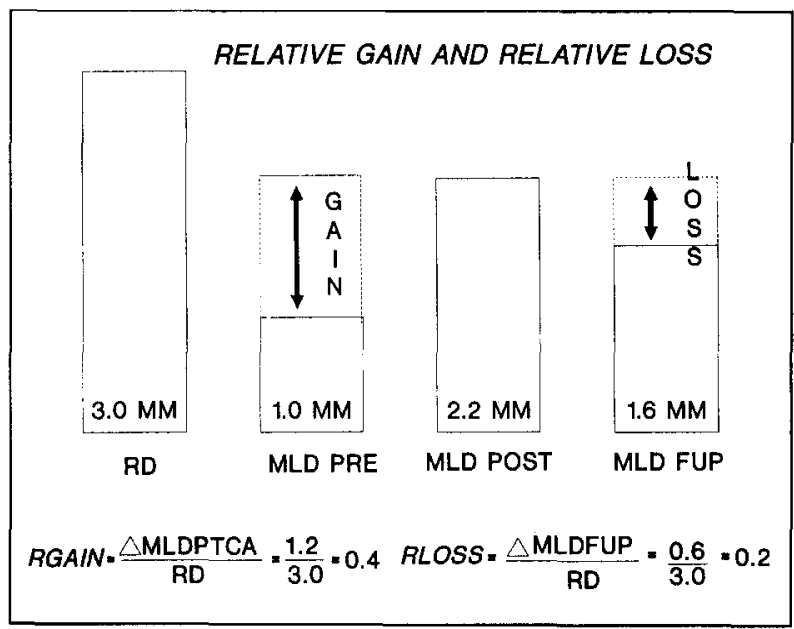

FIGURE 4. See text for explanation of relative gain (RGAIN) and relative lose (RLOSS). FUP = follow-LP; MLD = minimal huninal dlameter; POST = after; PRE = before; PTCA = percutaneous transhuminal coronary angioplasty; $\mathbf{R D}=$ reference diameter. 
although these new techniques have not yet succeeded in reducing restenosis rates. ${ }^{24,25}$ Several explanations have been put forward to explain the increased risk for restenosis in the (proximal) LAD. Mata et $\mathrm{al}^{8}$ believed that a high rate of "continuous success" needs an opti- mal selection of the balloon/artery ratio and optimal balloon pressure application. They suggested that anatomic or procedural factors were responsible for restenosis. Leimgruber et al ${ }^{10}$ had 3 possible explanations. First, because they believed that the proximal LAD is

TABLE II Baseline Quantitative Angiographic Data per Vessel Segment Dilated

\begin{tabular}{|c|c|c|c|c|c|c|c|}
\hline $\begin{array}{c}\text { Coronary } \\
\text { Artery }\end{array}$ & No. & $\begin{array}{l}\text { Pre PTCA RD } \\
\quad(\mathbf{m m})\end{array}$ & $\begin{array}{l}\text { Post PTCA RD } \\
(\mathrm{mm})\end{array}$ & $\begin{array}{l}\text { Follow-Up RD } \\
\qquad(\mathrm{mm})\end{array}$ & $\begin{array}{l}\text { Pre PTCA MLD } \\
(\mathrm{mm})\end{array}$ & $\begin{array}{l}\text { Post PTCA MLD } \\
(\mathrm{mm})\end{array}$ & $\begin{array}{c}\text { Follow-Up MLD } \\
\text { (mm) }\end{array}$ \\
\hline Total & 1,452 & $2.63 \pm 0.54$ & $2.70 \pm 0.52$ & $2.70 \pm 0.56$ & $1.02 \pm 0.38$ & $1.77 \pm 0.36$ & $1.50 \pm 0.57$ \\
\hline $\begin{array}{l}\text { Right } \\
\text { Proximal } \\
\text { Middle } \\
\text { Distal }\end{array}$ & $\begin{array}{r}414 \\
148 \\
174 \\
92\end{array}$ & $\begin{array}{l}2.86 \pm 0.55 \\
2.99 \pm 0.55 \\
2.82 \pm 0.50 \\
2.71 \pm 0.59\end{array}$ & $\begin{array}{l}2.93 \pm 0.52 \\
3.05 \pm 0.51 \\
2.90 \pm 0.50 \\
2.81 \pm 0.56\end{array}$ & $\begin{array}{l}2.97 \pm 0.58 \\
3.07 \pm 0.55 \\
2.94 \pm 0.59 \\
2.85 \pm 0.57\end{array}$ & $\begin{array}{l}1.08 \pm 0.41 \\
1.11 \pm 0.45 \\
1.08 \pm 0.41 \\
1.02 \pm 0.35\end{array}$ & $\begin{array}{l}1.91 \pm 0.37 \\
1.96 \pm 0.39 \\
1.91 \pm 0.34 \\
1.83 \pm 0.40\end{array}$ & $\begin{array}{l}1.65 \pm 0.65 \\
1.69 \pm 0.63 \\
1.66 \pm 0.65 \\
1.57 \pm 0.66\end{array}$ \\
\hline $\begin{array}{l}\text { LAD } \\
\text { Proximal } \\
\text { Middle } \\
\text { Distal }\end{array}$ & $\begin{array}{r}684 \\
288 \\
324 \\
72\end{array}$ & $\begin{array}{l}2.54 \pm 0.53 \\
2.73 \pm 0.52 \\
2.48 \pm 0.47 \\
2.08 \pm 0.44\end{array}$ & $\begin{array}{l}2.59 \pm 0.49 \\
2.78 \pm 0.48 \\
2.52 \pm 0.43 \\
2.14 \pm 0.44\end{array}$ & $\begin{array}{l}2.58 \pm 0.53 \\
2.76 \pm 0.53 \\
2.52 \pm 0.47 \\
2.13 \pm 0.42\end{array}$ & $\begin{array}{l}1.01 \pm 0.36 \\
1.08 \pm 0.35 \\
0.97 \pm 0.36 \\
0.87 \pm 0.35\end{array}$ & $\begin{array}{l}1.72 \pm 0.35 \\
1.83 \pm 0.35 \\
1.68 \pm 0.32 \\
1.43 \pm 0.29\end{array}$ & $\begin{array}{l}1.42 \pm 0.53 \\
1.53 \pm 0.55 \\
1.35 \pm 0.51 \\
1.29 \pm 0.37\end{array}$ \\
\hline $\begin{array}{l}\text { LC } \\
\text { Proximal } \\
\text { Middle } \\
\text { Distal }\end{array}$ & $\begin{array}{l}354 \\
101 \\
125 \\
128\end{array}$ & $\begin{array}{l}2.55 \pm 0.50 \\
2.73 \pm 0.47 \\
2.55 \pm 0.50 \\
2.41 \pm 0.49\end{array}$ & $\begin{array}{l}2.62 \pm 0.46 \\
2.75 \pm 0.43 \\
2.64 \pm 0.45 \\
2.50 \pm 0.46\end{array}$ & $\begin{array}{l}2.61 \pm 0.48 \\
2.74 \pm 0.44 \\
2.61 \pm 0.50 \\
2.52 \pm 0.48\end{array}$ & $\begin{array}{l}1.01 \pm 0.36 \\
1.06 \pm 0.42 \\
1.00 \pm 0.34 \\
0.98 \pm 0.34\end{array}$ & $\begin{array}{l}1.73 \pm 0.34 \\
1.82 \pm 0.32 \\
1.75 \pm 0.32 \\
1.63 \pm 0.34\end{array}$ & $\begin{array}{l}1.48 \pm 0.51 \\
1.52 \pm 0.50 \\
1.52 \pm 0.53 \\
1.41 \pm 0.49\end{array}$ \\
\hline
\end{tabular}

TABLE III Restenosis Rate per Segment Using the Categorical Definition of $>50 \%$ DS at Follow-Up, and the Continuous Approach with Relative Gain and Loss

\begin{tabular}{|c|c|c|c|c|c|}
\hline & \multirow[b]{2}{*}{ No. } & \multicolumn{2}{|c|}{ DS $(\%)$ at Follow-Up $>50 \%$} & \multirow[b]{2}{*}{ Relative Gain } & \multirow[b]{2}{*}{ Relative Loss } \\
\hline & & Yes & No & & \\
\hline Total & 1452 & $444(31)$ & $1008(69)$ & $0.29 \pm 0.16$ & $0.11 \pm 0.21$ \\
\hline $\begin{array}{l}\text { Right } \\
\text { Proximal } \\
\text { Middle } \\
\text { Distal }\end{array}$ & $\begin{array}{r}414 \\
148 \\
174 \\
92\end{array}$ & $\begin{array}{r}123(30) \\
45(30) \\
48(28) \\
30(33)\end{array}$ & $\begin{array}{r}289(70) \\
103(70) \\
126(72) \\
62(67)\end{array}$ & $\begin{array}{l}0.30 \pm 0.15 \\
0.29 \pm 0.15 \\
0.30 \pm 0.15 \\
0.31 \pm 0.15\end{array}$ & $\begin{array}{l}0.10 \pm 0.22 \\
0.10 \pm 0.21 \\
0.10 \pm 0.22 \\
0.11 \pm 0.26\end{array}$ \\
\hline $\begin{array}{l}\text { LAD } \\
\text { Proximal } \\
\text { Middle } \\
\text { Distal }\end{array}$ & $\begin{array}{r}684 \\
288 \\
324 \\
72\end{array}$ & $\begin{array}{r}224(33) \\
95(33) \\
114(35) \\
15(21)\end{array}$ & $\begin{array}{r}457(67) \\
193(67) \\
210(65) \\
57(79)\end{array}$ & $\begin{array}{l}0.29 \pm 0.17 \\
0.29 \pm 0.17 \\
0.29 \pm 0.17 \\
0.27 \pm 0.19\end{array}$ & $\begin{array}{l}0.12 \pm 0.20 \\
0.12 \pm 0.19 \\
0.13 \pm 0.21 \\
0.07 \pm 0.15\end{array}$ \\
\hline $\begin{array}{l}\text { LC } \\
\text { Proximal } \\
\text { Middle } \\
\text { Distal } \\
\text { p Value }\end{array}$ & $\begin{array}{c}354 \\
101 \\
125 \\
128 \\
\text { (right vs LAD vs LC) } \\
\text { (9 segments) }\end{array}$ & $\begin{array}{l}97(28) \\
33(33) \\
25(20) \\
40(31) \\
0.22 \\
0.06\end{array}$ & $\begin{array}{c}255(72) \\
68(67) \\
100(80) \\
88(69)\end{array}$ & $\begin{array}{c}0.29 \pm 0.16 \\
0.29 \pm 0.16 \\
0.30 \pm 0.15 \\
0.28 \pm 0.17 \\
0.44 \\
0.77\end{array}$ & $\begin{array}{c}0.11 \pm 0.21 \\
0.11 \pm 0.18 \\
0.09 \pm 0.21 \\
0.09 \pm 0.21 \\
0.13 \\
0.19\end{array}$ \\
\hline
\end{tabular}

TABLE IV Relative Gain and Loss per Reference Diameter Group

\begin{tabular}{|c|c|c|c|c|c|c|c|c|}
\hline \multirow[b]{2}{*}{$\mathrm{RD}(\mathrm{mm})$} & \multirow[b]{2}{*}{ No. } & \multirow[b]{2}{*}{ Absolute Gain (mm) } & \multirow[b]{2}{*}{ Relative Gain } & \multirow[b]{2}{*}{ Absolute Loss (mm) } & \multirow[b]{2}{*}{ Relative Loss } & \multicolumn{2}{|c|}{ DS $(\%)$ at Follow-Up $>50 \%$} & \multirow[b]{2}{*}{ BAR } \\
\hline & & & & & & Yes & No & \\
\hline$>4.0 \mathrm{~mm}$ & 18 & $0.72 \pm 0.55$ & $0.17 \pm 0.13$ & $0.13 \pm 0.46$ & $0.03 \pm 0.10$ & $6(33)$ & $12(67)$ & 0.77 \\
\hline 3.5 to $4.0 \mathrm{~mm}$ & 81 & $0.87 \pm 0.47$ & $0.24 \pm 0.13$ & $0.10 \pm 0.50$ & $0.03 \pm 0.13$ & $23(28)$ & $58(71)$ & 0.89 \\
\hline 3.0 to $3.5 \mathrm{~mm}$ & 222 & $0.83 \pm 0.42$ & $0.26 \pm 0.13$ & $0.33 \pm 0.54$ & $0.10 \pm 0.17$ & $71(32)$ & $151(68)$ & 0.97 \\
\hline 2.5 to $3.0 \mathrm{~mm}$ & 507 & $0.76 \pm 0.40$ & $0.28 \pm 0.15$ & $0.28 \pm 0.52$ & $0.10 \pm 0.19$ & $153(30)$ & $354(70)$ & 1.07 \\
\hline 2.0 to $2.5 \mathrm{~mm}$ & 454 & $0.72 \pm 0.40$ & $0.32 \pm 0.17$ & $0.28 \pm 0.51$ & $0.12 \pm 0.23$ & $148(33)$ & $306(67)$ & 1.20 \\
\hline$<2.0 \mathrm{~mm}$ & 170 & $0.61 \pm 0.34$ & $0.34 \pm 0.20$ & $0.27 \pm 0.46$ & $0.15 \pm 0.26$ & $44(26)$ & $126(74)$ & 1.39 \\
\hline Analysis of variance & & $<0.001$ & $<0.001$ & $<0.02$ & $<0.001$ & \multicolumn{2}{|c|}{ NS } & \\
\hline
\end{tabular}


most often the largest artery, the $3.0 \mathrm{~mm}$ diameter balloons most frequently used at that time could have been undersized for the LAD and oversized for the right coronary artery and LC. This resulted in increased diameter stenosis after PTCA, which seems to be associated with a higher risk for restenosis. Second, a dilatation of the proximal LAD often involves the origin of the vessel and vessel branch points, and this factor also appears to be associated with an increased risk of restenosis. Third, the proximal LAD is well-recognized to develop "localized stenosis." Whether the same underlying mechanisms may predispose a patient to recurrence of lesions after angioplasty is unknown but well-conceivable.

Because balloon/artery mismatch was not identified as a predictor for restenosis in a group of patients with multilesion coronary angioplasty, Vandormael et $\mathrm{al}^{13}$ suggested that the different anatomic and structural features of the proximal segment of the LAD compared with those of the proximal segment of the right coronary artery or LC may be responsible for the observation that dilatation of the proximal L.AD is an independent risk factor for restenosis.

According to Califf et al, ${ }^{3} 1$ of the methodologic caveats for an increased rate of restenosis in the proximal LAD was that an ischemic response to exercise testing was more likely to be seen with proximal LAD lesions, thereby increasing the chance of preferential detection unless angiographic follow-up was complete. Also, a larger diameter of this vessel may have increased the risk that a satisfactory initial result was not achieved in earlier series, especially before the recent development of larger balloons to approach large vessels.

In the present study, no significant difference in the restenosis rate was found among the 3 major coronary arteries $(p=0.22)$ or the 9 coronary artery segments $(p=0.06)$ selected for the purpose of analysis. Our results contradict the earlier observations of Leimgruber and Califf and their coworkers that the proximal LAD is the largest vessel. In the present study, almost every segment of the right coronary artery has a larger diameter than the proximal LAD. An explanation for this discrepancy may be the differences in patient populations; availability of different balloon sizes (with diameters $<2.0 \mathrm{~mm}$ as compared with those in the early days of PTCA when only balloon sizes of $3.7 \mathrm{~mm}$ were available) for dilatation may have affected PTCA of the proximal LAD. Another argument put forth in the early years that there was a mismatch between balloon catheters and proximal LAD is no longer valid, because in the present study, all patients underwent PTCA between December 1987 and December 1989 so that in all cases matched balloons were available. The differences in restenosis rates reported by these investigators are probably more related to the biased and incomplete angiographic follow-ups of these studies. In contrast, the present study has a $91 \%$ angiographic follow-up rate, and so the biased selection of symptomatic versus asymptomatic patients is virtually ruled out.

Definition of restenosis: The definition of restenosis has been the subject of much debate. ${ }^{4}$ Of the different restenosis criteria proposed, $>50 \%$ diameter stenosis at follow-up angiography is the most frequently used to assess restenosis, because physiologic measurements have shown that the threshold for chest pain is near a reduction of $50 \%$ of the lumen of a normal vessel. ${ }^{22}$ This definition was applied to our data. However, earlier studies have shown that the reference diameter can be involved in the dilatation process so that the \% diameter stenosis could underestimate the change in the severity of a stenosis after PTCA. ${ }^{26}$ Furthermore, the 50\% diameter stenosis criterion at follow-up reveals nothing about the way the lesion has behaved since the PTCA procedure. We have previously shown that a change $\geq 0.72 \mathrm{~mm}$ in minimal luminal diameter is an appropriate method to assess intimal hyperplasia after coronary PTCA. ${ }^{5,20,27}$ However, this criterion was historically assessed in vessels with an average reference diameter of $3.7 \mathrm{~mm} .{ }^{5,20}$ Therefore, it should be applied to vessels of comparable reference diameter; it is unlikely to have a decrease $\geq 0.72 \mathrm{~mm}$ in coronary segments with a reference diameter of $2 \mathrm{~mm}$, and a minimal luminal diameter of $1.4 \mathrm{~mm}$. In other words, criteria based on the absolute change in minimal luminal diameter are limited because they make no attempt to relate the extent of the restenosis process to the size of the vessel. To circumvent this limitation it was proposed to use the change in minimal luminal diameter from after PTCA to follow-up, normalized for the reference diameter (relative loss). This sliding scale criterion that adjusts for vessel size allows for regional assessment of the extent of the restenosis phenomenon in the entire coronary tree. No difference in relative loss among the 3 major coronary arteries $(p=0.13)$ or the coronary segments could be observed ( $p=0.19)$. Restenosis should thus be viewed as a ubiquitous phenomenon that is inducible to the same extent in every segment of the coronary tree. It must be emphasized that the relative gain (change in minimal luminal diameter from before to after PTCA, normalized for the reference diameter) and thus the stimulus for restenosis ${ }^{28}$ were similar in every segment of the coronary tree.

Because the subdivision of the American Heart Association-coronary segments is somewhat arbitrary in that vessels of different diameters are grouped together, we reanalyzed the data by stratifying the lesions according to their reference diameters. Table IV lists the results. It appears that the larger the reference diameter is before PTCA, the smaller the relative loss is at followup; vice versa, the greatest value of relative loss is observed in the smaller vessels. This may be explained by oversizing of the balloon in these vessels. However, if the restenosis criterion of $>50 \%$ diameter stenosis is used, then similar restenosis rates are found.

Potential limitation of the study: Our study population consisted mainly of patients with 1 dilatation site; 1,044 patients had 1 dilatation site, and 190 underwent dilatation of $\geq 2$ sites. The high incidence of 1 dilatation site reflects the fact that the study population included in these 2 trials consisted predominantly of patients with 1-vessel disease, so that our findings may not be extrapolated to a population with multivesscl diseasc. Nevertheless, in the subset of 93 patients with multivessel dilatation, the overall restenosis rate per lesion was also $31 \%$. However, the relative gain and loss observed in 
patients with 1- and 2-vessel dilatations differed statistically; a relative gain of $0.30 \pm 0.16$ was seen for 1 -vessel dilatation versus $0.27 \pm 0.16$ for 2 -vessel dilatation ( $p$ $<0.04$ ), and a relative loss of $0.12 \pm 0.21$ for 1 -vessel dilatation versus $0.08 \pm 0.20$ for 2 -vessel dilatation ( $p$ $<0.02$ ). Thus, in the population with 2-vessel dilatation, a reduced gain is associated with a reduced loss consistent with the concept that PTCA operators are less aggressive in their dilating strategy.

Acknowledgment: We gratefully acknowledge the statistical advice of Jaap Deckers, MD, the critical comments of Bradley Strauss, MD, and Donald MacLeod, MRCP, and the logistic help of Jaap Paameyer.

\section{REFERENCES}

1. Gruentzig AR, Senning A, Siegenthaler WE. Nonoperative dilatation of coronary artery stenosis. Percutaneous transluminal coronary angioplasty. $N E n g l J$ Med 1979;301;2:61-68.

2. Serruys PW, Rensing BJ, Luijten HE, Hermans WRM, Beatt KJ. Restenosis following coronary angioplasty. In: Meier B, ed. Interventional Cardiology. Bern, Switzcrland: Hogrefe and Huber, 1990:79-115.

3. Califf RM, Ohman EM, Frid DJ, Fortin DF, Mark DB, Hlatky MA, Herdon JE, Bengtson JR. Restenosis: the clinical issue. In: Topol E, ed. Textbook of Interventional Cardiology. New York: Saunders, 1990:363-394.

4. Beatt KJ, Serruys PW, Hugenholtz PG. Restenosis after coronary angioplasty: new standards for clinical studies. J Am Coll Cardiol 1990;15:491-498.

5. Reiber JHC, Serruys PW. Quantitative angiography. In: Marcus ML, Schelbert HR, Skorton DJ, Wolf GL, eds. Cardiac Imaging, a Companion to Braunwalds Heart Disease. New York: Saunders, 1991:211-280.

6. Holmes DR, Vlietstra RE, Smith HC, Vetrovec GW, Kent K, Cowley MI Faxon DP, Gruentzig AR, Kelsey SF, Detre KM, Raden MJ, van Mock MB. Restenosis after percutaneous transluminal coronary angioplasty (PTCA): a report from the angioplasty registry of the National Heart I ung and Blood Institute. Am J Cardiol 1984;53:77C-81C.

7. Kaltenbach M, Kober G, Scherer D, Vallbracht C. Recurrence rate after successful coronary angioplasty. Eur Heart $J$ 1985;6:276-281.

8. Mata LA, Bosch X, David PR, Rapold HJ, Corcos T, Bourassa MG. Clinical and angiographic assessment 6 months after double vessel percutaneous coronary angioplasty. I Am Coll Cardiol 1985;6:1239-1244.

9. DiSciascio G, Cowley MJ, Vetrovec GW. Angiographic patterns of restenosis after angioplasty of multiple coronary arteries. Am J Cardiol 1986;58:922-925. 10. Leimgruber PP. Roubin GS, Holiman J. Cotsonis GA. Meier B, Douglas JS King SB III, Gruentzig AR. Restenosis after successful coronary angioplasty in patients with single-vessel disease. Circulation 1986;73:710-717.

11. Myler RK, Topol EJ, Shaw RE, Stertzer SH, Clark DA, Fishman J, Murphy MC. Multiple vessel coronary angioplasty in 494 consecutive patients. Cathet Cardiovasc Diagn 1987;13:1-15.

12. Val PG, Bourassa M, David PR, Bonan R, Crépeau J, Dydra I, Lespérance J. Restenosis after successful percutaneous transluminal coronary angioplasty: the Montreal Heart Institute Experience. Am J Cardiol 1987;60:50B-55B.
13. Vandormael MG, Deligonul U, Kern M, Harper M, Presant S, Gibson $P$, Galan K, Chaitman BR. Multilesion coronary angioplasty: clinical and angiographic follow-up. J Am Coll Cardiol 1987;10:246-252.

14. Black AJR, Anderson HV, Roubin GS, Powelson SW, Douglas JS Jr, King SB III. J Am Coll Cardiol 1988;11:714-718.

15. De Feyter PJ, Suryapranata H, Serruys PW, Beatt K, van Domburg R, van den Brand M, Tijssen JJ, Azar AJ, Hugenholtz PG. Coronary angioplasty for unstable angina: immediate and late results in 200 consecutive patients with identification of risk factors for unfavorable early and late outcome. $J \mathrm{Am}$ Coll Cardiol 1988; 12:324-333.

16. Fleck E, Regitz V, Lehnert A, Dacian S, Dirschinger J, Rudolph W. Restenosis after balloon dilatation of coronary stenosis: multivariate analysis of potential risk factors. Eur Heart $J$ 1988;9(suppl C):15-18.

17. Quigley PJ, Hlatjy MA, Hinohara T, Rendall DS, Perez JA, Philips HR, Califf RM, Stack RS. Repeat percutaneous transluminal coronary angioplasty and predictors of recurrent restenosis. Am J Cardiol 1989:63:409-413.

18. Renkin J, Melin J, Robert A, Richelee F, Bachy J, Col J, Detry JR, Wijns W. Detection of restenosis after successful coronary angioplasty: improved clinical decision making with use of a logistic model combining procedural and follow-up variables. J Am Coll Cardiol 1990;16:1333-1340.

19. Rupprecht HJ, Brennecke R, Bernhard G, Erbel R, Pop T, Meyer J. Analysis of risk factors for restenosis after PTCA. Cathet Cardiovasc Diagn 1990;19: 151-159.

20. Reiber JHC, Serruys PW, Kooyman CJ, Wijns W, Slager CJ, Gerbrands JJ, Schuurbiers JCH, den Boer A, Hugenholtz PG. Assessment of short, medium and long term variations in arterial dimensions from computer assisted quantification of coronary cineangiograms. Circulation 1985;71:280-288.

21. Austen WG, Edwards JE, Frye RL, Gensini GG, Gott VK, Griffith LSC, McGoon DC, Murphy ML, Roe BB. A reporting system on patients evaluated for coronary artery disease. Report of the adhoc committee for grading of coronary artery disease, council on cardiovascular surgery, American Heart Association. Circulation 1975;51:7-40.

22. Gould KL, Lipscombe K. Effects of coronary stenoses on coronary flow reserve and resistance. Am J Cardiol 1974;33:87-94.

23. Topol EJ. Promises and pitfalls of new devices for coronary artery disease (editorial). Circulation 1991;83:689-694.

24. Serruys PW, Strauss BH, Beatt KJ, Bertrand ME, Puel J, Rickards AF, Meier B, Goy JJ, Vogt P, Kappenberger L, Sigwart U. Angiographic follow-up after placement of a self-expanding coronary artery stent. $N$ Engl $J$ Med 1991;324:13-17.

25. Schatz RA, Baim DS, Leon M, Ellis SG, Goldberg S, Hirshfeld JW, Cleman MW, Cabin HS, Walker C, Stagg J, Buchbinder M, Teirstein PS, Topol EJ, Savage M, Perez JA, Curry RC, Whitworth H, Sousa JE, Tio F, Almagor Y, Ponder R, Penn IM, Leonard B, Levine SL, Fish RD, Palmaz JC. Clinical experience with the Palmaz-Schatz coronary stent. Initial results of a multicenter study. Circulation 1991;83:148-161.

26. Beatt KJ, Luijten HE, de Feyter PJ, van den Brand M, Reiber JHC, Serruys PW, ten Katen $\mathrm{HJ}$, van Es GA. Change in diameter of coronary artery segments adjacent to stenosis after percutaneous transluminal coronary angioplasty. Failure of percent diameter stenosis measurements to reflect morphologic changes induced by balloon dilatation. J Am Coll Cardiol 1988;12:315-323.

27. Serruys PW, Luijten HE, Beatt KJ, Geuskens R, de Feyter P, van den Brand M, Reiber JHC, ten Katen HJ, van Es GA, Hugenholtz PG. Incidence of restenosis after successful angioplasty: a time related phenomenon. Circulation 1988; 77:361-371.

28. Beatt $K$ Serruys PW, Luijten HE, Rensing BJ, Suryapranata $H$, de Feyter $P$, van den Brand M, Laarman GJ, Roelandt J, van Es GA. Restenosis following coronary angioplasty. The paradox of improvement in lumen diameter. $\mathrm{J} \mathrm{Am} \mathrm{Coll}$ Cardiol: in press. 